\title{
Solubilization of Potassium Containing Various K-Mineral Sources by K-Solubilizing Bacterial Isolates on Aleksandrov Medium
}

\author{
Shilpa Singh ${ }^{1}$, Bihari Ram Maurya ${ }^{1}$ and Indra Bahadur ${ }^{1,2^{*}}$
}

${ }^{1}$ Department of Soil Science and Agricultural Chemistry, Institute of Agricultural Sciences, Banaras Hindu University, Varanasi 221005, Uttar Pradesh, India

${ }^{2}$ Soil and Land Use Survey of India, Ministry of Agriculture and Farmers Welfare, Govt. of India, Kolkata Centre-700 094, India

*Corresponding author

\section{A B S T R A C T}

\begin{tabular}{|l|}
\hline Ke y w o r d s \\
$\begin{array}{l}\text { Solubilization, Isolates, } \\
\text { Silicate mineral, Silica } \\
\text { and Mica }\end{array}$ \\
\hline Article Info \\
\hline $\begin{array}{l}\text { Accepted: } \\
\text { 10 February } 2018 \\
\text { Available Online: } \\
\text { 10 March } 2018\end{array}$ \\
\hline
\end{tabular}

\section{Introduction}

The development of intensively managed agriculture has led to the consumption of increasing amounts of $\mathrm{K}$ in many parts of India. As a result now the soils those are Kdeficient or present in unavailable form to plant. The low K supply has become the main yield limiting factor in agriculture. Potassium though present in abundant quantity in soil but only $1-2 \%$ of this is available to plants, the rest being bound with other minerals and is therefore unavailable to plants (Bahadur et al., 2015). For optimal nutrition of a crop, the replenishment of a K-depleted soil solution is
Aim of our research study to find out efficient strains of K-solubilizing bacteria from potassium solubilizing isolates under in-vitro condition and different source of potassium minerals. The morpho-biochemical characterization and mica-K solubilization capacity of $\mathrm{K}$-solubilizers bacterial in-vitro was done. Effect of K-solubilizing bacterial isolates on $\mathrm{pH}$, EC soluble $\mathrm{K}$ and residual silica at 7, 14, 21 and 28 days after incubation in broth containing mica was studied. A significant increase in $\mathrm{K}$ solubilization on mica containing broth was achieved by inoculation of different isolates of potassium solubilizing bacteria (KSB). Among the 10 isolate tested, maximum $3.11 \mu \mathrm{g} \mathrm{mL}^{-1} \mathrm{~K}$ was obtained with $\mathrm{KSB} 38$ isolate at 21. Results of the present investigation show that KSB44, KSB38, KSB51, KSB11 and KSB30 emerged out as efficient K-solubilizers. affected predominantly by the release of exchangeable $\mathrm{K}$ from clay minerals. Consequently, for maximal crop growth, soil solution and exchangeable $\mathrm{K}$ need to be replenished continually with $\mathrm{K}$ through the release of non-exchangeable $\mathrm{K}$ through the weathering of $\mathrm{K}$ reserves i.e. micas and feldspars (Sparks and Huang, 1985). Total soil $\mathrm{K}$ reserves are generally large although the distribution of $\mathrm{K}$ forms differs from soil to soil. Potassium in soil is present in four forms viz., water soluble or solution $\mathrm{K}$, exchangeable $\mathrm{K}$, non-exchangeable $\mathrm{K}$ and structural or minerals K. Soil minerals make up more than 90 to $98 \%$ of the soil potassium (Goldstein 
1994). It is tightly bound and most of it is unavailable for plant uptake. The second is non-exchangeable $\mathrm{K}$ consists predominantly of interlayer $\mathrm{K}$ present largely within nonexpanded clay minerals such as illite, vermiculite, chlorite and become available to plant with relative difficulty whereas $\mathrm{K}$ present in lattice of $\mathrm{K}$-minerals such as $\mathrm{K}$ feldspars and K-mica release $\mathrm{K}$ through weathering (Meena et al., 2015). It makes up approximately 1 to $10 \%$ of soil potassium which acts as a reserve to replenish potassium in soil. The third and fourth types are available potassium which contributes 1-2 \% are potassium water-soluble $\mathrm{K}$ and exchangeable $\mathrm{K}$. This form of $\mathrm{K}$ is directly available for plant uptake. Exchangeable $\mathrm{K}$ or available $\mathrm{K}$ is held in the solid phase of soil, on clay minerals and organic matter by electrostatic forces and easily move into the soil solution through exchange with other cation (Maurya et al., 2014). Soil solution $\mathrm{K}$ is the primary form of potassium from which plant takes up $\mathrm{K}^{+}$ion. The concentration of potassium needed by plants depends upon the crop grown and demand of crop. Mass flow is a process largely involved in supplying of potassium to crop plants followed by diffusion.

Most Indian soils are fairly rich in $\mathrm{K}$ resources as primary and secondary clay minerals and increasing $\mathrm{K}$ availability for plant production. However, available $\mathrm{K}$ in some Indian soils is not sufficient for high K-demand crops such as potato, soybean and tomato which may be potentially improved by the application of KSB. In India, very few reports are available on the ability of some bacterial species to solubilizing potassium (Datta et al., 2010; Gaur and Ostwal 1973). However, none of the research works have identified a microorganism suitable as a bio-inoculant for potassium solubilization. Until now, there are no reports in any of the scientific publications about a suitable potassium solubilizing bio- inoculant. At present in India, no recommendations are made by government organizations to the farmers about potassium solubilizing bio-inoculant for the fulfillment of potassium requirement. Thus application of $\mathrm{KSB}$ is a promising approach for increasing $\mathrm{K}$ availability in soils cultivated for high $\mathrm{K}$ demand crops (Zahra et al., 1984). However, information on mobilization of $\mathrm{K}$ in mined waste mica and their use as K-fertilizer for crop production is still lacking.

\section{Materials and Methods}

A total of 10 isolates showing zone of solubilization on Aleksandrov agar media were further examined for their ability to release of $\mathrm{K}$ from mica in broth culture. Two $\mathrm{ml}$ of overnight broth culture of each isolate was inoculated to $100 \mathrm{~mL}$ of Aleksandrov broth containing $0.3 \mathrm{~g}$ powdered mica in three replicates. All the inoculated flasks were incubated for 7 days, 14 days, 21days and 28 days in BOD at $\left(28 \pm 2^{0} \mathrm{C}\right)$ temperature. The amount of potassium released which was solubilized by the isolates in the broth was estimated and compared with un-inoculated control. The isolates were inoculated in the broth which produces organic acids according to their ability. Organic acid production is proportional to its incubation time. Organic acids lower down the $\mathrm{pH}$ value of broth culture. Broths are filtered through Whatman No.1 filter paper and filtrate was taken in the $50 \mathrm{~mL}$ beaker. The $\mathrm{pH}$ of broth for different isolates was examined with the help of digital pH meter (Chopra and Kanwar, 1982). Same culture filtrate, after estimation of $\mathrm{pH}$ was used to determine the $\mathrm{EC}$ of the filtrate using digital EC meter. 10 isolates were studied for their potassium solubilizing capacity at an interval of 7, 14, 21 and 28 days of incubation by following the procedure as described above. Simultaneously, a standard curve was prepared using various concentrations of $\mathrm{KCl}$ solution. The amount of potassium solubilized 
by the isolates was calculated from the standard curve through automated flame photometer. After filtration of broth media clear supernatant was used for determination of potassium and filtrate was washed 3 times with $5 \mathrm{~N}$ HCL then filter paper was dry burned in flame and kept in muffle furnace at $400^{\circ} \mathrm{C}$ for 5 hours after cooling weigh the crucibles with mica in weighing balance. The raw data generated during the whole experiment were subject to statistical analysis by following the Factorial Complete Randomized Design (FCRD) to draw the valid differences among the treatments.

\section{Results and Discussion}

The economic status of developing country like India and its huge investments in importing potassium fertilizers has thrown light on the development of an alternative measure which are more eco-bio-friendly. The concentrations of soluble potassium in the soil are usually very low and more than $98 \%$ of potassium in the soil exists in the form of insoluble rocks and silicate minerals. Finding the efficient $\mathrm{K}$-solubilizing bacterial isolates to diminish the load on chemical fertilizers would be a strategical measure to overcome this issue.

\section{Periodical pH changes of Aleksandrov broth medium}

The $\mathrm{pH}$ of the broth culture was studied at 7 , 14, 21 and 28 days of incubation of isolates (Table 1). The decrease in the $\mathrm{pH}$ values of broth culture media was recorded with increase in the activity of bacterial isolates and as we move from 7 to 21 days there was decrease in $\mathrm{pH}$ of broth medium. The KSB isolates produces organic acids which was also reported by Liu et al.,(2006), which is considered to be the prime reason for the decrease of $\mathrm{pH}$ of broth. The result is also in agreement with the findings of $\mathrm{Hu}$ et al.,
(2006). Minimum pH 6.27was recorded at 28 days after incubation which was significantly lower than 7, 14 and 21 days of incubation.

The $\mathrm{pH}$ value of the culture with respect to control slightly decreases with incubation time (Archana et al., 2008). All isolates have significantly lowered the $\mathrm{pH}$ values over control. Isolate KSB 38 was found to have lowered the $\mathrm{pH}$ value to about 6.27 at 28 days which was significantly superior to all other isolates followed by KSB 11 and KSB 1 . Among the examined isolates five isolates viz. KSB 1, KSB 11, KSB 16, KSB 38 and KSB 51 showed $\mathrm{pH}$ values less than 6.5 . The acidic effect was due to production of different organic acids like citric acid, tartaric acid, fumaric acid which specifically break down mineral structure and extract elements required for metabolism or structure purpose (Girgis et al., 2008). Interaction between isolates and incubation period was found to be significant.

\section{Periodical changes in electrical conductivity of Aleksandrov broth medium}

Electrical conductivity of the broth culture was studied at 7, 14, 21 and 28 days after incubation (DAI). The isolates produce organic substances during their metabolic processes which resulted to increase of soluble salts of broth culture resulting increase of EC of broth. Electrical conductivity of isolate, ranged from 0.05 to $0.16 \mathrm{dSm}^{-1}$ (Table 2). Among the isolates KSB 51 has maximum electrical conductivity $\left(0.16 \mathrm{dSm}^{-1}\right)$ at 21 days followed by KSB13 $\left(0.15 \mathrm{dSm}^{-1}\right)$, which were significantly superior to other isolates of potassium solubilizing bacteria. Three isolates showed electrical conductivity more than 0.11 $\mathrm{dSm}^{-1}$. The EC values of the culture in experiments during the incubation period increased significantly with incubation periods. Maurya et al., (2016) also reported that increase in incubation period Electrical 
conductivity of the medium increases. The electrical conductivity was slightly decreases at 28 days in some bacteria after incubation and minimum EC at 7 days after incubation. Interaction effect of incubation period and isolates were significant and maximum value was observed at 21 days after incubation by isolate KSB51 which was significantly superior to other isolates. Isolate no. KSB11 has minimum EC value $0.06 \mathrm{dSm}^{-1}$ at 7 days after incubation. EC at 7 days after incubation ranged from 0.05 to $0.9 \mathrm{dSm}^{-1}$. Similar findings were also noticed by Saha et al., (2016).

\section{Periodical release of potassium from mined muscovite}

Release of potassium from mica by all isolates significantly increases with increase in incubation period upto 21 days and then decreases at 28 DAI except in isolate KSB 64 in which an indefinite release of $\mathrm{K}$ was seen which is maximum at 14 DAI and then decreased (Fig. 1). In all other isolates higher amount of release of $\mathrm{K}$ was observed at 21 days of incubation followed by 14 days of incubation and lowest k-released was observed at 7 and 28 days of incubation After 21 days it was found that there was drastic decrease in release of potassium by isolates. Results indicated that all the K- Solubilizers potentially promote solubilization of $\mathrm{K}$, this is in agreement with the findings of Hutchens et al., (2003); He and Sheng (2006). The amount of $\mathrm{K}$ released by the isolates from mined mica in Aleksandrov broth was studied at 7, 14 and 21 days and 28 days after incubation (DAI).

The K-released from mined mica by the isolates at 7 DAI ranged from 1.06 to $1.89 \mu \mathrm{g}$ $\mathrm{mL}^{-1}$. The $\mathrm{K}$ released from mined mica by isolates at 14 DAI ranged from 1.21 to $1.96 \mu \mathrm{g}$ $\mathrm{mL}^{-1}$ which was significantly superior over the value recorded with control. Release of $\mathrm{K}$ from mined mica at 21 DAI was found to be significantly higher in all isolates except in
$\mathrm{KSB}$ and ranges from 1.28 to $3.11 \mu \mathrm{g} \mathrm{mL} \mathrm{m}^{-1}$ where isolate KSB 38 was found to have highest release of $\mathrm{K}$ from mined mica which was significantly found to be superior over all other isolates. $\mathrm{K}$ is found to be easily released from mined mica. Amount of $\mathrm{K}$ released at 28 DAI ranged from 0.46 to $1.46 \mu \mathrm{g} \mathrm{mL}^{-1}$. Result of interaction effect was found to be significant. Inoculation of KSB along with mica has been potentially found to release significantly higher amount of $\mathrm{K}$ over control (Basak and Biswas 2010).

Five isolates viz. KSB 11, KSB 16, KSB 38, KSB 44 and KSB 51 showed more than $1.6 \mu \mathrm{g}$ $\mathrm{mL}^{-1}$ of K-solubilization from mica.

The mechanism of potassium solubilization depends on release of organic acid, production of protons, organic ligand this is in agreement with findings of Basak and Biswas (2009), Maurya et al., (2014) and Bahadur et al., (2016). Degradation activity of isolates also depends on the slime production Sugumaran and Janarthanam (2007). K-solubilization increased with increasing of incubation periods up to 21 days and then decreases at 28 days.

Isolate KSB 38 gave maximum $\mathrm{K}(3.11 \mu \mathrm{g} \mathrm{K}$ $\mathrm{mL}^{-1}$ ) at 21 days of inoculation which was significantly superior to all other interaction values. All the isolates of KSB are found to be significant at 21 days except at 28 days of inoculation where only some of the isolate shows better result. Isolate KSB 38 shows a drastic decrease at 28 days due to overgrowth of bacterial culture in broth media resulting in fixing of $\mathrm{K}$ in the bacterial cell.

\section{Residual silica contents in Aleksandrov medium containing mica}

The amount of residual silica content by the isolates ranged from 0.256 to $0.298 \mathrm{~g}$ in broth (Table 3). 
Fig.1 Effect of KSB isolates on release of $\mathrm{K}\left(\mu \mathrm{gmL}^{-1}\right)$ from mica at different days of incubation

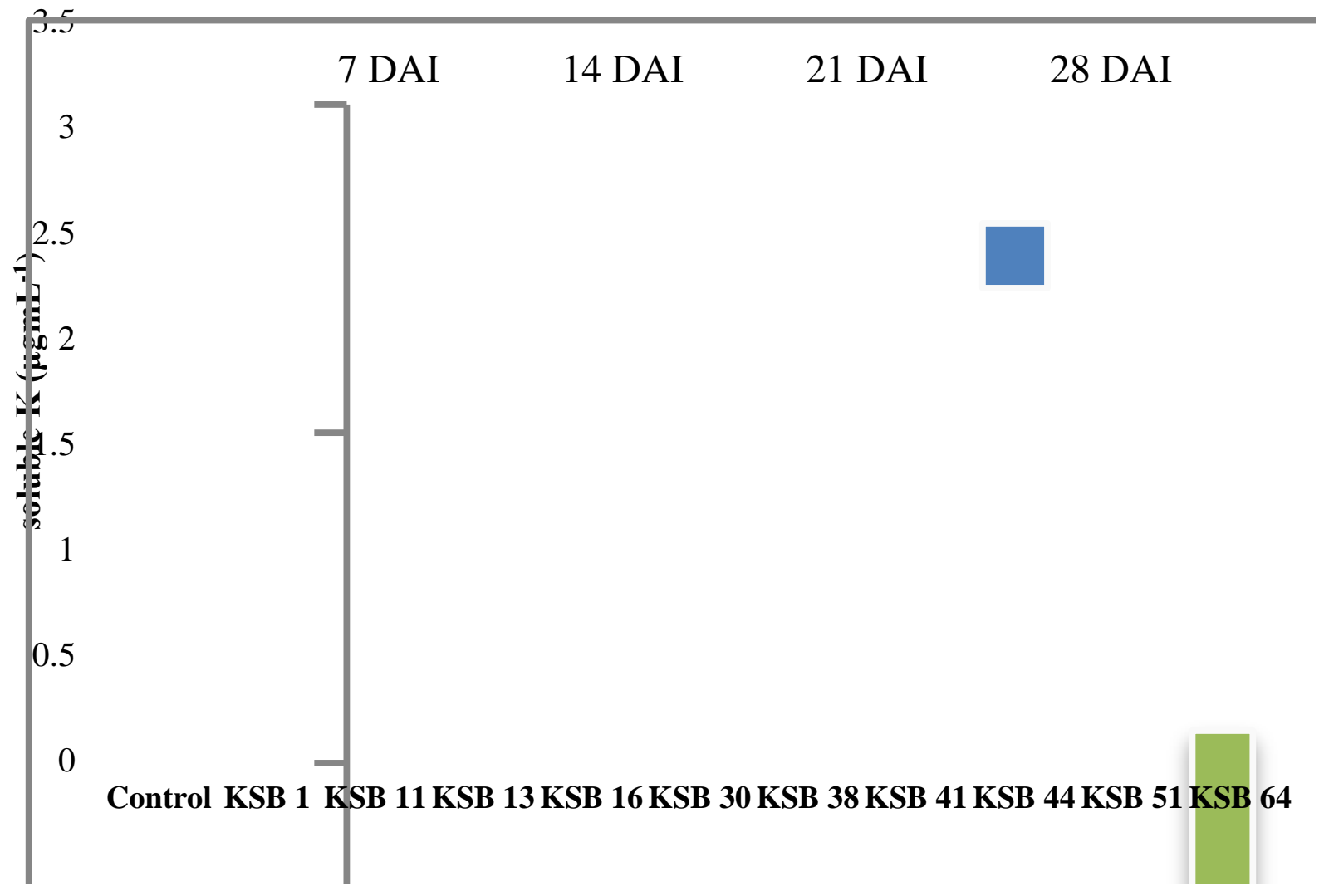

Table.1 Effect of KSB isolates on $\mathrm{pH}$ at different days of incubation

\begin{tabular}{|c|c|c|c|c|c|}
\hline Isolates & 7 DAI & 14 DAI & $21 \mathrm{DAI}$ & 28 DAI & Mean \\
\hline Control & 7.00 & 6.97 & 7.00 & 7.10 & 7.02 \\
\hline KSB 1 & 6.67 & 6.50 & 6.43 & 6.37 & 6.49 \\
\hline KSB 11 & 6.53 & 6.40 & 6.40 & 6.33 & 6.42 \\
\hline KSB 13 & 6.77 & 6.62 & 6.43 & 6.40 & 6.55 \\
\hline KSB 16 & 6.60 & 6.52 & 6.43 & 6.40 & 6.49 \\
\hline KSB 30 & 6.67 & 6.57 & 6.47 & 6.47 & 6.54 \\
\hline KSB 38 & 6.50 & 6.45 & 6.40 & 6.27 & 6.41 \\
\hline KSB 41 & 6.67 & 6.52 & 6.50 & 6.43 & 6.53 \\
\hline KSB 44 & 6.63 & 6.57 & 6.50 & 6.60 & 6.58 \\
\hline KSB 51 & 6.60 & 6.48 & 6.43 & 6.40 & 6.48 \\
\hline KSB 64 & 6.70 & 6.59 & 6.50 & 6.47 & 6.56 \\
\hline \multirow[t]{2}{*}{ Mean } & 6.67 & 6.56 & 6.50 & 6.48 & - \\
\hline & \multicolumn{3}{|c|}{$\mathrm{SEm} \pm$} & \multicolumn{2}{|c|}{$\mathrm{CD}(\mathrm{P}=0.01)$} \\
\hline Isolate & \multicolumn{3}{|c|}{0.01} & \multicolumn{2}{|c|}{0.05} \\
\hline Day & \multicolumn{3}{|c|}{0.01} & \multicolumn{2}{|c|}{0.03} \\
\hline Isolate $\times$ Day & \multicolumn{3}{|c|}{0.02} & \multicolumn{2}{|c|}{0.09} \\
\hline
\end{tabular}


Table.2 Effect of KSB isolates on EC $\left(\mathrm{dSm}^{-1}\right)$ of mined muscovite mica broth at different days of incubation

\begin{tabular}{|l|c|c|c|c|c|}
\hline \multicolumn{1}{|c|}{ Isolates } & 7 DAI & 14 DAI & 21 DAI & 28 DAI & Mean \\
\hline Control & 0.06 & 0.07 & 0.07 & 0.05 & 0.06 \\
\hline KSB 1 & 0.08 & 0.09 & 0.13 & 0.07 & 0.09 \\
\hline KSB 11 & 0.06 & 0.08 & 0.11 & 0.09 & 0.08 \\
\hline KSB 13 & 0.08 & 0.09 & 0.15 & 0.11 & 0.11 \\
\hline KSB 16 & 0.07 & 0.07 & 0.11 & 0.11 & 0.09 \\
\hline KSB 30 & 0.08 & 0.08 & 0.11 & 0.09 & 0.09 \\
\hline KSB 38 & 0.08 & 0.08 & 0.10 & 0.09 & 0.09 \\
\hline KSB 41 & 0.07 & 0.08 & 0.09 & 0.08 & 0.08 \\
\hline KSB 44 & 0.08 & 0.09 & 0.09 & 0.09 & 0.09 \\
\hline KSB 51 & 0.09 & 0.08 & 0.16 & 0.11 & 0.11 \\
\hline KSB 64 & 0.08 & 0.09 & 0.10 & 0.09 & 0.09 \\
\hline Mean & 0.08 & 0.08 & 0.11 & 0.09 & - \\
\hline & & SEm \pm & & CD $(\mathrm{P}=0.01)$ \\
\hline Isolate & & 0.0005 & & 0.002 & \\
\hline Day & & 0.0002 & & 0.001 & \\
\hline Isolate $\times$ Day & & 0.001 & & 0.003 & \\
\hline
\end{tabular}

Table.3 Effect of KSB isolates on residual silica contents (g) in Aleksandrov medium containing mica at different incubation period

\begin{tabular}{|c|c|c|c|c|c|}
\hline Isolates & 7 DAI & $14 \mathrm{DAI}$ & 21 DAI & 28 DAI & Mean \\
\hline Control & 0.298 & 0.297 & 0.297 & 0.297 & 0.297 \\
\hline KSB 1 & 0.262 & 0.257 & 0.255 & 0.253 & 0.257 \\
\hline KSB 11 & 0.270 & 0.256 & 0.253 & 0.251 & 0.257 \\
\hline KSB 13 & 0.261 & 0.255 & 0.253 & 0.252 & 0.255 \\
\hline KSB 16 & 0.267 & 0.257 & 0.254 & 0.248 & 0.256 \\
\hline KSB 30 & 0.264 & 0.254 & 0.253 & 0.253 & 0.256 \\
\hline KSB 38 & 0.263 & 0.255 & 0.246 & 0.242 & 0.251 \\
\hline KSB 41 & 0.262 & 0.259 & 0.256 & 0.253 & 0.257 \\
\hline KSB 44 & 0.272 & 0.257 & 0.252 & 0.251 & 0.258 \\
\hline KSB 51 & 0.256 & 0.251 & 0.250 & 0.247 & 0.251 \\
\hline KSB 64 & 0.262 & 0.258 & 0.258 & 0.255 & 0.258 \\
\hline Mean & 0.267 & 0.259 & 0.257 & 0.255 & - \\
\hline & \multicolumn{2}{|c|}{$\mathrm{SEm} \pm$} & & \multicolumn{2}{|c|}{$\mathrm{CD}(\mathrm{P}=0.01)$} \\
\hline Isolate & \multicolumn{2}{|c|}{0.001} & & \multicolumn{2}{|c|}{0.002} \\
\hline Day & \multicolumn{2}{|c|}{0.000} & & \multicolumn{2}{|c|}{0.001} \\
\hline Isolate $\times$ Day & \multicolumn{2}{|c|}{0.001} & & \multicolumn{2}{|c|}{0.003} \\
\hline
\end{tabular}




\section{Int.J.Curr.Microbiol.App.Sci (2018) 7(3): 1142-1151}

Table.4 Correlation between $\mathrm{pH}, \mathrm{EC}, \mathrm{K}$, and residual silica

\begin{tabular}{|c|c|c|c|c|c|c|c|c|c|c|c|c|c|c|c|c|}
\hline & \multicolumn{4}{|c|}{$\mathrm{pH}$} & \multicolumn{4}{|c|}{$\mathrm{EC}$} & \multicolumn{4}{|c|}{$\mathrm{K}$} & \multicolumn{4}{|c|}{$\mathrm{Si}$} \\
\hline & ph7 & ph14 & ph21 & $\mathrm{ph} 28$ & EC7 & EC14 & EC21 & EC28 & K7 & K14 & $\mathrm{K} 21$ & K28 & Sil & Si14 & $\mathrm{Si} 21$ & $\mathrm{Si} 28$ \\
\hline ph7 & 1 & 0.170 & $0.361^{*}$ & 0.120 & -0.123 & -0.107 & -0.149 & 0.013 & $-0.362^{*}$ & -0.053 & -0.069 & 0.275 & $0.402^{*}$ & $0.480^{* *}$ & $0.462^{* *}$ & $0.472^{* *}$ \\
\hline ph14 & & 1 & $0.694^{* *}$ & -0.156 & $-0.379^{*}$ & -.117 & $-0.565^{* *}$ & $-0.390^{*}$ & -0.319 & -0.336 & $-0.387^{*}$ & 0.161 & $0.782^{* *}$ & $0.772^{* *}$ & $0.708^{* *}$ & $0.704^{* *}$ \\
\hline ph21 & & & 1 & -0.184 & -0.316 & -.259 & $-0.505^{* *}$ & -.213 & -0.257 & -0.204 & -0.222 & 0.243 & $0.761^{* *}$ & $0.761^{* *}$ & $0.764^{* *}$ & $0.765^{* *}$ \\
\hline ph28 & & & & 1 & $0.384^{*}$ & $0.359^{*}$ & 0.246 & .130 & $0.398^{*}$ & 0.107 & -0.264 & -0.013 & -0.334 & -0.269 & -0.312 & -0.322 \\
\hline EC 7 & & & & & 1 & 0.074 & 0.304 & -0.206 & $0.440^{*}$ & 0.226 & 0.139 & 0.013 & $-0.401^{*}$ & $-0.427^{*}$ & $-0.357^{*}$ & $-0.359^{*}$ \\
\hline EC14 & & & & & & 1 & $0.394^{*}$ & 0.292 & 0.012 & -0.010 & -0.114 & -0.023 & -0.287 & -0.302 & -0.288 & -0.284 \\
\hline EC21 & & & & & & & 1 & $0.408^{*}$ & 0.211 & 0.077 & 0.192 & 0.063 & $-0.691^{* *}$ & $-0.698^{* *}$ & $-0.694^{* *}$ & $-0.692^{* *}$ \\
\hline EC28 & & & & & & & & 1 & 0.165 & 0.112 & -0.093 & -0.195 & $-0.363^{*}$ & $-0.367^{*}$ & -0.308 & -0.297 \\
\hline K7 & & & & & & & & & 1 & 0.344 & 0.029 & $-0.535^{* *}$ & $-0.467^{* *}$ & $-0.478^{* *}$ & $-0.493^{* *}$ & $-0.501^{* *}$ \\
\hline K14 & & & & & & & & & & 1 & 0.045 & -0.152 & -0.247 & -0.261 & -0.256 & -0.253 \\
\hline K21 & & & & & & & & & & & 1 & -0.075 & -0.210 & -0.203 & -0.199 & -0.196 \\
\hline K28 & & & & & & & & & & & & 1 & 0.159 & 0.144 & 0.171 & 0.182 \\
\hline Si7 & & & & & & & & & & & & & 1 & $0.967^{* *}$ & $0.941^{* *}$ & $0.934^{* * *}$ \\
\hline Si14 & & & & & & & & & & & & & & 1 & $0.952^{*}$ & $0.962^{* *}$ \\
\hline $\mathrm{Si} 21$ & & & & & & & & & & & & & & & 1 & $0.967 *$ \\
\hline $\mathrm{Si} 28$ & & & & & & & & & & & & & & & & 1 \\
\hline
\end{tabular}

7, 14, 21 and 28 are Days of Incubation **Significant at 1\%, *. Significant at 5\% (EC=electrical Conductivity, Si=Silica, K=Potassium) 
At 7, 14, 21 and 28 days of incubation content of residual silica in broth ranged from 0.256 $0.298 \mathrm{~g}, \quad 0.251-0.297 \mathrm{~g}, \quad 0.246-0.297 \mathrm{~g}$ and $0.242-0.297 \mathrm{~g}$ respectively. All the isolates significantly decreased content of residual silica in broth. Isolate KSB51 caused lowest silica content at 7 and 14 days of incubation that was significantly lower than other isolates. Likewise KSB38 caused significantly lesser residual silica at 21 and 28 DAI compared to other isolates. Decrease in residual silica content with increase in incubation period. Residual silica content was negatively correlated to the release of soluble $\mathrm{K}\left(\mu \mathrm{g} \mathrm{mL} \mathrm{m}^{-1}\right)$. As the amount of residual silica is more the release of soluble $\mathrm{K}$ was found to be less. KSB 38 was found to release maximum amount of soluble $\mathrm{K}\left(\mu \mathrm{g} \mathrm{mL}{ }^{-1}\right)$ at 21 DAI. KSB 51 and KSB 44 also showed the significant release of soluble $\mathrm{K}\left(\mu \mathrm{g} \mathrm{mL}^{-1}\right)$ with respect to control.

\section{Correlation between potassium and $\mathrm{pH}$}

Lowering of $\mathrm{pH}$ is due to release of organic acids which caused release of potassium from insoluble mica. The decrease in the $\mathrm{pH}$ value of broth is related to activity of bacterial isolates on Aleksandrov broth media which is also related to increase in potassium concentration of bacterial isolate (Table 4). Negative correlation between $\mathrm{pH}$ and released $\mathrm{K}$ from $\mathrm{K}$-minerals is also reported Archana et al., (2008).

\section{Correlation between potassium and electrical conductivity}

Potassium and EC was found to be positively correlated explained in (Table 1). This showed that increase $\mathrm{K}$ concentration in broth caused increase in electrical conductivity of broth. This is due to production of organic substance by the isolates during their metabolic processes which increased soluble salts in broth culture resulting in increase in electrical conductivity. During experiment it was observed that potassium and EC of broth media increases with increase in incubation period.

\section{Correlation between potassium and residual silica}

Potassium concentration increased when residual silica content decreased with incubation period. Even in control low concentration of residual silica was observed. Thus a significant negative correlation between concentration of potassium and residual silica content can be observed. This is due to release of $\mathrm{K}$ from insoluble soil mineral (i.e. mica) which can be used to examine isolate ability for mineral dissolution. Such type of correlation also has been reported by Friedrich et al., (1991).

Interaction effect of isolates and incubation period on $\mathrm{pH}$ was found to be significant. With increase in incubation period $\mathrm{pH}$ value of broth decreased due to production of organic acids by the isolates. KSB 38 showed lowest $\mathrm{pH}$ value (6.27) at 28 DAI. At 7, 14, 21days of inoculation significant decrease in $\mathrm{pH}$ was observed while at 28 days of inoculation non-significant decrease was observed. Significant increase in EC was obtained with increase in incubation periods. Potassium solubilizing bacterial isolated significantly influenced the release of $\mathrm{K}$ from mica from 7 to 21 DAI. However, release of $\mathrm{K}$ from mica was insignificantly higher at 28 days of incubation. Interaction effect was found significant and KSB 38showed maximum release of $K$ at 21 DAI $(3.11 \mu \mathrm{g}$ $\mathrm{mL}^{-1}$ ). A significant decrease in silica content was recorded with increase in incubation period. Isolate KSB 38 gave lowest residual silica content. A non-significant decrease in Si content was recorded with respect to the incubation period. Interaction of isolates with days of incubation was found to be significant 
and KSB 51 showed lowest residual silica content at 28 DAI. Content of residual content of silica is inversely related to the quantity of $\mathrm{K}$ released from waste mica.

\section{Acknowledgements}

Authors are sincere thankful to the Head, Department of Soil Science and Agricultural Chemistry, Institute of Agricultural Sciences, Banaras Hindu University for providing facility during experiment.

\section{Conflict of interest}

The authors did not declare any conflict of interest.

\section{References}

Archana, D.S., Savalgi, V.P. and Alagawadi, A.R. 2008. Effect of potassium solubilizing bacteria on growth and yield of maize. Soil Biology \&Ecology. 28, 9-18.

Bahadur, I., Maurya, B.R., Kumar, S., Dixit J., Chauhan, A.S., Manjhi, B.K., Meena V.S., and Narayan, S.R.P. 2015. The Novel Potassic Bio-Fertilizers: A Promising Approach for Evergreen Agriculture. International Journal of microbiology Research. 7(5): 692-697.

Bahadur, I., Maurya, B.R., Meena, V.S., Saha, M., Kumar, A. and Aeron, A. 2016. Minerals release dynamics of tricalcium phosphate (TCP) and waste muscovite (WM) by mineral solubilizing rhizobacteria (MSR) isolated from Indo-Gangetic Plain (IGP) of India. Geomicrobiology Journal. DOI: 10.1080/01490451.2016.1219431.

Basak, B.B. and Biswas, D.R. 2009. Influence of potassium solubilizing microorganism (Bacillus mucilaginosus) and waste mica on potassium uptake dynamics by Sudan grass (Sorghum vulgare Pers.) grown under two Alfisols. Plant and Soil.317, $235-255$.

Basak, B.B. and Biswas, D.R. 2010. Coinoculation of potassium solubilizing and nitrogen fixing bacteria on solubilization of waste mica and their effect on growth promotion and nutrient acquisition by a forage crop. Biology and Fertility of Soils.46, 641-648.

Chopra, S.L., Kanwar, J.S. 1982. Analytical Agricultural Chemistry. Kalyani Publishers, New Delhi, India.

Datta, S.C. 2010. Potassium dynamics and status in Indian soil. Karnataka Journal Agricultural Sciences.24, 7-11.

Friedrich, S., Plantonova, N.P., Karavaiko, G.I., Stichel, E. and Glombitza, F. 1991. Chemical and microbial solubilization of silicates. Biotechnology.11, 187-196.

Gaur, A.C. and Ostwal, K.P. 1973. Influence of phosphate dissolving Bacilli on yield and phosphate uptake of wheat crop. Indian Journal of Experimental Biology10, 393-394.

Girgis, M.G.Z., Heba, Khalil, M.A. and Sharaf, M.S. 2008.In Vitro Evaluation of Rock Phosphate and Potassium Solubilizing Potential of Some Bacillus Strains. Australian Journal of Basic and Applied Science. 2(1), 68-81.

Goldstein, A.H. 1994. Involvement of the quino protein glucose dehydrogenase in the solubilizing of exogeneous mineral phosphates by gram negative bacteria. In phosphate in microorganisms: cellular and molecular biology. Cell Molecular Biology. 197-203.

He, Lin Y., Sheng, Fang, X. 2006. Solubilization of potassium-bearing minerals by a wild-type strain of Bacillus edaphicus and its mutants and increased potassium uptake by wheat. Canadian Journal of Microbial.52, 66-72. 
Hu, X., Chen, J. and Guo, J. 2006. Two phosphate-and potassium-solubilizing bacteria isolated from Tianmu Mountain, Zhejiang, China. World journal of Microbiology and Biotechnology. 22(9): 983-990.

Hutchens, S.E., Valsami, J.E. and Eldowney, M.Sc 2003. The role of heterotrophic bacteria in feldspar dissolution. Mineral Magic.67, 1151-1170.

Liu, W., Xu, X., Wu, S., Yang, Q., Luo, Y. And Christie, P. 2006. Decomposition of silicate minerals by Bacillus mucilaginosus in liquid culture. Environmental Geochemistry and Health.28, 133-140.

Maurya, B.R., Meena, V.S. and Meena, O.P. 2014. Influence of Inceptisol and Alfisol's Potassium Solubilizing Bacteria (KSB) isolates on release of $\mathrm{K}$ from waste mica. Vegetos. 27(1): 181187.

Meena, V.S., Maurya, B.R. and Verma, J.P. 2015. Does a rhizospheric microorganism enhance $\mathrm{K}+$ availability in agricultural soils? Microbiological Research.169, 337-347.

Saha, M., Maurya, B.R., Meena, V.S., Bahadur, I. and Kumar, A. 2016.Identification and characterization of potassium solubilizing bacteria (KSB) from Indo-Gangetic Plains of India, Biocatalysis and Agricultural Biotechnology.7, 202-209.

Sparks, and Huang, P.M. 1985. Physical chemistry of soil potassium. In Potassium in agriculture (ed.) Munson, R.D., American Society of Agronomy Journal 201-276.

Sugumaran, P. and Janarthanam, B. 2007. Solubilization of potassium containing minerals by bacteria and their effect on plant growth. World Journal of Agricultural Sciences. 3, 350-355.

Zahra, M. K., Monib, M.S., Abdel-Al, I., Heggo, A. 1984. Significance of soil inoculation. Mikrobiology. 139, 349357.

\section{How to cite this article:}

Shilpa Singh, Bihari Ram Maurya and Indra Bahadur. 2018. Solubilization of Potassium Containing Various K-Mineral Sources by K-Solubilizing Bacterial Isolates on Aleksandrov Medium. Int.J.Curr.Microbiol.App.Sci. 7(03): 1142-1151. doi: https://doi.org/10.20546/ijcmas.2018.703.136 